\title{
ÁREAS VERDES URBANAS E TRILHAS ECOLÓGICAS COMO LOCAIS E INSTRUMENTOS DE EDUCAÇÃO AMBIENTAL
}

\author{
Pedro Rosso ${ }^{1}$ \\ Erica Mastella Benincá ${ }^{2}$ \\ Fernando Bueno Ferreira Fonseca de Fraga ${ }^{3}$ \\ Gilberto Tonetto ${ }^{4}$
}

Resumo: É urgente combater a degradação e o esgotamento dos recursos naturais e equacionar o crescimento urbano com a manutenção de áreas verdes. Neste contexto, desde 2014 a trilha ecológica criada na área verde do IFSC Câmpus Criciúma vem sendo utilizada em atividades de Educação Ambiental com o objetivo de promover a cultura do desenvolvimento sustentável. Este artigo relata estas ações. A trilha tem $350 \mathrm{~m}$ e conta com materiais informativos e educativos. Os grupos visitantes são recepcionados no laboratório de biologia, onde realizam atividades lúdicas, e depois participam de visita guiada à trilha. Até 2019 foram atendidas cerca de 1.500 pessoas e as atividades são registradas em um blog, que possui mais de 5.700 visitas.

Palavras-chave: Desenvolvimento Sustentável; Educação Ambiental; Áreas Verdes Urbanas; Trilhas Ecológicas.

Abstract: It is urgent to combat the degradation and depletion of natural resources and to equate urban growth with green areas maintenance. In this context, since 2014 the ecological trail created in the green area of IFSC Campus Criciúma has been used in environmental education activities with the aim of promoting the culture of sustainable development. This article reports on these actions. The trail is $350 \mathrm{~m}$ long and has informative and educational materials. The visiting groups are received at the biology laboratory, where they carry out recreational activities, and then participate in a guided tour of the trail. Until 2019, approximately 1,500 people were served and the activities are recorded in a blog, which has more than 5,700 visits.

Keywords: Sustainable Development; Environmental Education; Urban Green Areas; Ecological Trails.

\footnotetext{
1 Instituto Federal de Santa Catarina. E-mail: pedro.rosso@ifsc.edu.br.

2 Instituto Federal de Santa Catarina. E-mail: erica.beninca@ifsc.edu.br.

3 Instituto Federal de Santa Catarina. E-mail: fernando.bueno@ifsc.edu.br

${ }^{4}$ Instituto Federal de Santa Catarina. E-mail: gilberto.tonetto@ifsc.edu.br
} 


\section{Introdução}

O pensamento predominante até pouco tempo atrás era de que o ser humano deveria se esforçar para conhecer a natureza para poder subjugá-la de acordo com seus propósitos (FIGUEIREDO, 2013) e essa é ainda uma ideia defendida por muitos. Como consequência desse comportamento e do modelo produtivo originado a partir da revolução industrial, ampliaram-se os impactos negativos no meio ambiente, motivados, principalmente, pela exigência de matérias-primas e o aumento da exploração dos recursos naturais.

A preocupação com a degradação ambiental, o risco de colapso ecológico e o avanço da desigualdade e da pobreza são sinais eloquentes da crise ambiental mundial e tiveram seu primeiro lapso de emergência quando da realização, em junho de 1972, da Conferência das Nações Unidas sobre o Meio Ambiente Humano, em Estocolmo, na Suécia (LEFF, 2004). Nas últimas cinco décadas, outros eventos e incontáveis estudos foram realizados com objetivo de discutir os impactos das atividades humanas sobre os ecossistemas e propor caminhos para um desenvolvimento mais equilibrado, isto é, um desenvolvimento capaz de suprir as necessidades da geração atual sem comprometer a capacidade de atender as necessidades das gerações futuras (ROMEIRO, 2012).

O conceito de desenvolvimento sustentável surgiu a partir da expressão "ecodesenvolvimento", cunhada nos anos 1970 como resultado do esforço para encontrar uma alternativa possível entre desenvolvimentistas e defensores do crescimento zero (ROMEIRO, 2012). Essa proposta defendia um desenvolvimento pautado no tripé justiça social, equilíbrio ecológico e viabilidade econômica. Por meio do desenvolvimento sustentável almeja-se que todos os cidadãos possam ter o mínimo necessário para uma vida digna e que ninguém consuma bens e recursos naturais e energéticos que sejam prejudiciais a outros (NASCIMENTO, 2012).

Contudo, apesar dos avanços nas últimas décadas, a humanidade encontra-se num momento de enormes desafios para 0 desenvolvimento sustentável, pois o esgotamento dos recursos naturais e os impactos negativos da degradação ambiental acrescentam e exacerbam a lista dos problemas a serem enfrentados (UNDP, 2016). Nesse sentido, visando estimular a adoção de práticas para um desenvolvimento sustentável, a Organização das Nações Unidas para a Educação, a Ciência e a Cultura (UNESCO) elaborou, em 2015, uma proposta com 17 objetivos, conhecidos como Objetivos para 0 Desenvolvimento Sustentável (ODS), com o desafio de que sejam alcançados até o ano de 2030 (UNDP, 2016).

Diante dessas questões, somadas a preocupação de promover a cultura do desenvolvimento sustentável por meio de atividades de Educação Ambiental, uma equipe de servidores do Instituto Federal de Santa Catarina (IFSC), Câmpus Criciúma, lançou a ideia de utilizar a área verde existente dentro do Câmpus. Nesse espaço, a criação de uma trilha ecológica foi a alternativa adotada para desenvolver projetos que permitissem atender

revista brasileira educação ambiental 
demandas de diferentes públicos com atividades de extensão, ensino e pesquisa.

Importa ressaltar que a área verde e, consequentemente, a trilha ecológica estão inseridas no Bioma Mata Atlântica, protegido pela Lei n. 11.428/2006 (BRASIL, 2006), e que nela se encontram espécies da vegetação nativa em processo de regeneração. Além disso, a área constitui uma pequena porção da mata ciliar do rio Linha Anta, protegida pela Lei n. 12.727/2012 (BRASIL, 2012). Apesar do tamanho da área ser de aproximadamente 12 mil $\mathrm{m}^{2}$, ela está imbricada em um espaço que requer "uma transformação significativa na forma de construir e gerenciar os espaços urbanos" (UNDP, 2016). Assim, é nesse cenário que se desenvolveram entre 2014 e 2019 os projetos de Educação Ambiental aqui relatados com o propósito de sensibilizar o público-alvo a atuar como cidadãos de em uma sociedade que dê mais atenção as áreas verdes inseridas nos espaços urbanos

\section{A urbanização e os ecossistemas}

No contexto do modelo econômico urbano-industrial, o processo de urbanização acelerou-se a partir da segunda metade do século XVIII e promoveu grandes impactos nos ecossistemas, sobretudo porque a expansão das cidades sempre foi vista como símbolo do progresso (FIALHO, 2012). O crescimento das cidades provoca modificações na paisagem que afetam as condições essenciais à vida, tais como a água, o solo e o ar (FIALHO, 2012), ao mesmo tempo em que causa a redução das áreas verdes, embora estas sejam reconhecidas como importantes indicadores de qualidade ambiental urbana (BARGOS; MATIAS, 2011).

No Brasil, o processo de urbanização foi mais intenso ao longo do litoral e impactou de modo mais significativo o bioma Mata Atlântica, uma das florestas mais biodiversas e ameaçadas do planeta (SOS MATA ATLÂNTICA, 2020). Atualmente, restam apenas $12,4 \%$ da floresta original, que era de $1.315 .460 \mathrm{~km}^{2}$, e sobre ela se concentram $72 \%$ da população brasileira, $70 \%$ do Produto Interno Brasileiro (PIB) e três dos maiores centros urbanos da América do Sul (SOS MATA ATLÂNTICA, 2020).

No sul de Santa Catarina, a exploração do carvão na chamada Bacia Carbonífera Catarinense ${ }^{5}$ transformou a região em uma das áreas com maior impacto ambiental do Brasil. A degradação ambiental iniciou com a exploração do carvão mineral em escala industrial nas primeiras décadas do século $X X$, mas se tornou mais significativa a partir de década de 1970 (RAVAZZOLI, 2013), com o aumento da mecanização das minas e, consequentemente, da

\footnotetext{
${ }^{5}$ A Bacia Carbonífera Catarinense corresponde a uma faixa de aproximadamente $100 \mathrm{~km}$ de comprimento e uma largura média de $20 \mathrm{~km}$ situada entre a Serra Geral a Oeste e o maciço granítico da Serra do Mar a Leste, seguindo a orientação Norte-Sul (BELOLLI; QUADROS; GUIDI, 2002). 
produção. O comprometimento da qualidade socioambiental alcançou proporções alarmantes, principalmente nos índices de poluição do sistema hídrico (GONÇALVES; MENDONÇA, 2007), sendo que as comunidades tiveram que aprender a conviver com a poluição do carvão que atingiu seus rios e lençol freático, além de afetar a atmosfera e a paisagem de toda a região (RAVAZZOLI, 2013).

Inseridos nesse contexto, os municípios de Criciúma e Içara (os dois maiores da região) contam com aproximadamente 270 mil habitantes (IBGE, 2020a; IBGE, 2020b), dos quais mais de $98 \%$ e 92\%, respectivamente, estão na área urbana (IBGE, 2010). A urbanização da região se acentuou nas últimas cinco décadas e, em paralelo, as áreas verdes urbanas ficaram mais escassas. Essas condições são evidentes obstáculos à produção de um espaço inclusivo, seguro, resiliente e sustentável, conforme preconizado no objetivo 11 da Agenda Universal 2030 (UNDP, 2016). Mesmo considerando todas as ações já desenvolvidas para minimizar os impactos da atividade carbonífera, estes ainda são muito presentes.

No que tange a urbanização e aos ecossistemas, é fundamental pensar em estratégias que considerem a sustentabilidade, pois

A sustentabilidade global obriga a pensar o substrato ecológico onde se assenta a cidade, a encará-la como um processo entrópico; a relacionar a construção do urbano (habitação, transporte, etc.) em função da qualidade do ambiente que ele gera e de seu impacto na degradação do ambiente pelo consumo de recursos; a considerar o fato urbano em sua dimensão territorial como um sistema de assentamentos em relação com seu ordenamento ecológico e com o ambiente global; a conceber o contínuo urbano-regional como uma conjunção de funções produtivas e de consumo, políticas e culturais (LEFF, 2004, p. 290).

Entende-se que é necessário planejar uma cidade considerando os ecossistemas e suas potencialidades. Isso não resolverá todos os problemas provocados pela crescente urbanização, mas não fazê-lo implicará em aumento dos problemas e na precarização da sustentabilidade ambiental das cidades.

\section{Áreas verdes, trilhas ecológicas e Educação Ambiental}

O crescimento das cidades, como já mencionado, é visto por muitos como símbolo do progresso, porém esse processo causa muitas modificações na paisagem (FIALHO, 2012). A vegetação, diferentemente da terra, do ar e da água, não é uma necessidade fundamental do meio urbano, embora a cobertura vegetal seja um atributo importante no desenvolvimento das cidades (NUCCl, 2008).

revista brasileira educação ambiental 
Não há um consenso sobre a definição do que são áreas verdes urbanas e muitas expressões têm sido utilizadas nos meios científicos com a mesma finalidade, entre as quais são encontradas: "áreas verdes", "espaços/áreas livres", "arborização urbana" e "verde urbano" (BARGOS; MATIAS, 2011). De todo modo, uma área verde é sempre um espaço livre, seja de propriedade pública ou privada, que tem como objetivo implantar ou preservar a vegetação, visando resguardar as condições ambientais (CAVALHEIRO; DEL PICHIA, 1992). Morero, Santos e Fidalgo (2007) entendem que as áreas verdes englobam os locais onde predomina a vegetação arbórea, as praças, jardins e parques. No Brasil, segundo as mesmas autoras, os poucos habitats naturais presentes nos centros urbanos estão continuamente sujeitos a ação antrópica e vêm experimentando uma crescente pressão imobiliária em paralelo com 0 crescimento intenso, desordenado e incontrolado das periferias (MORERO, SANTOS; FIDALGO, 2007).

Nesse contexto, as áreas verdes vêm ganhando importância com um dos elementos que pode contribuir na melhoria da qualidade de vida nas cidades (COSTA; COLESANTI, 2011), pois é lembrada pela maioria dos cidadãos mais pela sua função de satisfação psicológica e cultural do que por suas funções biofísicas (NUCCl, 2008). A importância das áreas verdes na qualidade de vida das populações urbanas está, principalmente, na sua contribuição para o equilíbrio entre o espaço urbanizado e o meio ambiente (SILVA; LIMA, 2017). Em relação aos benefícios à saúde física e psíquica proporcionados pelas áreas verdes, Rocha e Nucci (2018) destacam o estímulo à prática de atividades físicas, o favorecimento da sociabilidade, a redução do estresse, de comportamentos agressivos e do déficit de atenção em crianças e adolescentes. Entre os benefícios ambientais, a vegetação atua na estabilização das superfícies, no controle da radiação solar direta, na proteção da qualidade da água ao reduzir o escoamento de poluentes para os corpos d'água, no fornecimento de sombreamento, na regulação da umidade relativa do ar e do solo, na filtração e redirecionamento dos ventos, na estabilização da temperatura do ar, na redução da poluição do ar, na atenuação dos ruídos e ao proporcionar a existência de várias espécies vivas (ROCHA; NUCCl, 2018).

Um dos modos mais comuns para conhecer e usufruir das áreas verdes urbanas é a realização de caminhadas por trilhas com diferentes níveis de dificuldades. Caminhos e trilhas foram histórica e culturalmente utilizados pelas sociedades humanas com as mais diferentes finalidades, seja para busca de água e alimentos, vias de deslocamentos, acesso a pontos estratégicos e/ou atrativos naturais ou simplesmente para lazer e recreação (CARVALHO; BÓÇON, 2004; MACIEL et al., 2011; EISENLOHR et al., 2013). Caminhar longe do agito e da perturbação dos centros urbanos é um dos passatempos favoritos de um grande número de pessoas (BELART, 1978 apud CARVALHO; BÓÇON, 2004). As visitas em um ambiente natural são, em geral, realizadas por trilhas previamente delimitadas e mantidas de acordo com o objetivo de cada sítio e as trilhas interpretativas têm sido utilizadas tanto para recreação 
quanto para Educação Ambiental (CARVALHO; BÓçON, 2004).

As trilhas interpretativas, sejam guiadas ou não, são espaços usados para explicações sobre o meio ambiente, flora, fauna, fenômenos naturais e outros tantos temas ligados ao ambiente natural (GUILLAUMON et al., 1977 apud COLMAN; LORENCINI JÚNIOR; VAN DAL, 2017). Assim, quando bem planejadas, as trilhas interpretativas são importantes instrumentos pedagógicos e têm sido cada vez mais utilizadas em atividades de Educação Ambiental (CARVALHO; BÓÇON, 2004). Estas atividades, de maneira geral, fomentam a aquisição de conhecimentos e habilidades relativas ao meio ambiente e contribuem para a construção de hábitos e atitudes saudáveis. As trilhas interpretativas favorecem a percepção do ambiente como um espaço dinâmico e em constante mudança, onde as ações humanas, na maioria das vezes, causam impactos negativos ao ciclo natural (COLMAN; LORENCINI JÚNIOR; VAN DAL, 2017).

A expressão "Educação Ambiental" tornou-se conhecida mundialmente em um encontro da União Internacional para a Conservação da Natureza (IUCN), realizado na cidade de Paris em 1942, mas seu real significado começou a ser definido a partir da Conferência de Estocolmo (HENRIQUES et al., 2007). Uma das definições mais conhecidas no Brasil é a que consta na Política Nacional de Educação Ambiental (PNEA), instituída pela Lei no 9.795/1999, que define Educação Ambiental como "os processos por meio dos quais o indivíduo e a coletividade constroem valores sociais, conhecimentos, habilidades, atitudes e competências voltadas para a conservação do meio ambiente, bem de uso comum do povo, essencial à sadia qualidade de vida $e$ sua sustentabilidade" (BRASIL, 1999).

Para Sorrentino et al. (2005, p. 288),

A Educação Ambiental nasce como um processo educativo que conduz a um saber ambiental materializado nos valores éticos e nas regras políticas de convívio social e de mercado, que implica a questão distributiva entre benefícios e prejuízos da apropriação e do uso da natureza. Ela deve, portanto, ser direcionada para a cidadania ativa considerando seu sentido de pertencimento e corresponsabilidade que, por meio da ação coletiva e organizada, busca a compreensão e a superação das causas estruturais e conjunturais dos problemas ambientais.

Sorrentino et al. (2005) também afirmam que a Educação Ambiental é uma das possíveis estratégias para o enfrentamento da crise civilizatória cultural e social e "sua perspectiva crítica e emancipatória visa à deflagração de processos nos quais a busca individual e coletiva por mudanças culturais e sociais estão dialeticamente indissociadas" (SORRENTINO et al., 2005, p. 285). Para Jacobi (2003), a Educação Ambiental é a condição necessária para 
modificar um quadro de crescente degradação socioambiental, pois tem papel importante na transformação das pessoas, o que é fundamental para a promoção do desenvolvimento sustentável. Nesse contexto, é necessária uma mudança de atitude em relação à sustentabilidade ambiental, pois isto impulsiona diversas práticas com o objetivo de promover a consciência ambiental (ROSSO et al., 2020).

Para Rufino (2002, apud BARTICELLI; PANDOLFO; KORF, 2017), a Educação Ambiental é um processo em que se trabalham compromissos e conhecimentos capazes de levar o indivíduo a repensar sua relação com o meio e a mudar de atitudes em prol da melhoria da qualidade de vida da sociedade, bem como reverter situações que possam comprometer a sobrevivência e a manutenção da vida no planeta. Nesse sentido, a Educação Ambiental é instrumento fundamental para estimular a mudança das atitudes e dos valores que estão impregnados no ser humano e para catalisar o envolvimento de todos na melhoria na qualidade de vida e na proteção do meio ambiente (HENRIQUE; ROSSO, 2006).

Neste sentido, o projeto de extensão "Na trilha do desenvolvimento sustentável", desenvolvido no IFSC Câmpus Criciúma com o objetivo de promover a cultura do desenvolvimento sustentável por meio de atividades de Educação Ambiental em trilha ecológica, está diretamente vinculado à promoção da mudança de atitudes, especialmente das gerações futuras, uma vez que seu público-alvo é, predominantemente, de estudantes do Ensino Fundamental. Nesse caso, a Educação Ambiental desenvolvida em trilha ecológica inserida numa área verde urbana desperta essa tomada de consciência frente ao meio natural, proporcionando desenvolvimento de apreço e respeito para com a própria área verde e, a partir daí, estimulando essas atitudes frente a outros lugares.

Inúmeras experiências de Educação Ambiental, realizadas em diferentes contextos geográficos e culturais, têm contribuído efetivamente para ampliar a consciência ambiental da população, embora muitas sequer foram registradas e/ou publicadas. Nesse contexto enquadram-se atividades desenvolvidas por educadores em diferentes instituições de ensino, em organizações governamentais ou não governamentais, em parques públicos e privados e em áreas protegidas, entre outros locais, as quais nem sempre alcançam uma publicação que Ihes garanta divulgação e reconhecimento para além do seu público-alvo.

Os trabalhos que são publicados, entretanto, evidenciam a importância do uso de trilhas na Educação Ambiental, como o realizado por Mette, Silva e Tomio (2010), no município de Blumenau, SC. Os autores realizaram uma pesquisa com estudantes do $5^{\circ}$ ano de uma escola pública em que os estudantes participaram de um estudo em uma trilha próxima à escola e localizada em um fragmento florestal de Mata Atlântica. Ao final da pesquisa, os autores constataram que, após as atividades na trilha com utilização da metodologia de interpretação de desenhos e roteiros de observação, os 
estudantes demonstraram, por meio de registros e depoimentos, uma mudança de percepção em relação àquele fragmento florestal e às questões ambientais em geral. Outro exemplo, relatado por Buzatto e Kuhnen (2019), é de um projeto de extensão que teve como objetivo promover a Educação Ambiental a partir de uma trilha interpretativa em fragmento de Mata Atlântica localizado no Câmpus de Frederico Westphalen da Universidade Regional Integrada do Alto Uruguai e das Missões. O projeto empregou metodologia interdisciplinar com o uso de jogos pedagógicos e atendeu cerca de 1000 alunos do Ensino Fundamental e Médio de escolas do município de Frederico Westphalen e região, além de jovens aprendizes do programa Serviço Nacional de Aprendizagem Comercial (SENAC).

\section{A experiência de Educação Ambiental na Trilha IFSC}

O Câmpus Criciúma do Instituto Federal de Santa Catariana (IFSC) foi inaugurado em 2010 e está situado em um terreno de aproximadamente 40 mil $\mathrm{m}^{2}$, localizado próximo ao limite entre os municípios de Criciúma e Içara. Esse terreno fica no perímetro urbano conurbado dos dois municípios, e uma parte significativa dele, com aproximadamente $12 \mathrm{mil} \mathrm{m}^{2}$, corresponde a uma área verde cujas características fitofisionômicas pertencem a Floresta Ombrófila Densa Submontana, Domínio Mata Atlântica (VELOSO; KLEIN, 1968) (Figura 1). Esta área está diretamente associada ao rio Linha Anta, afluente da margem direita da bacia hidrográfica do rio Urussanga.

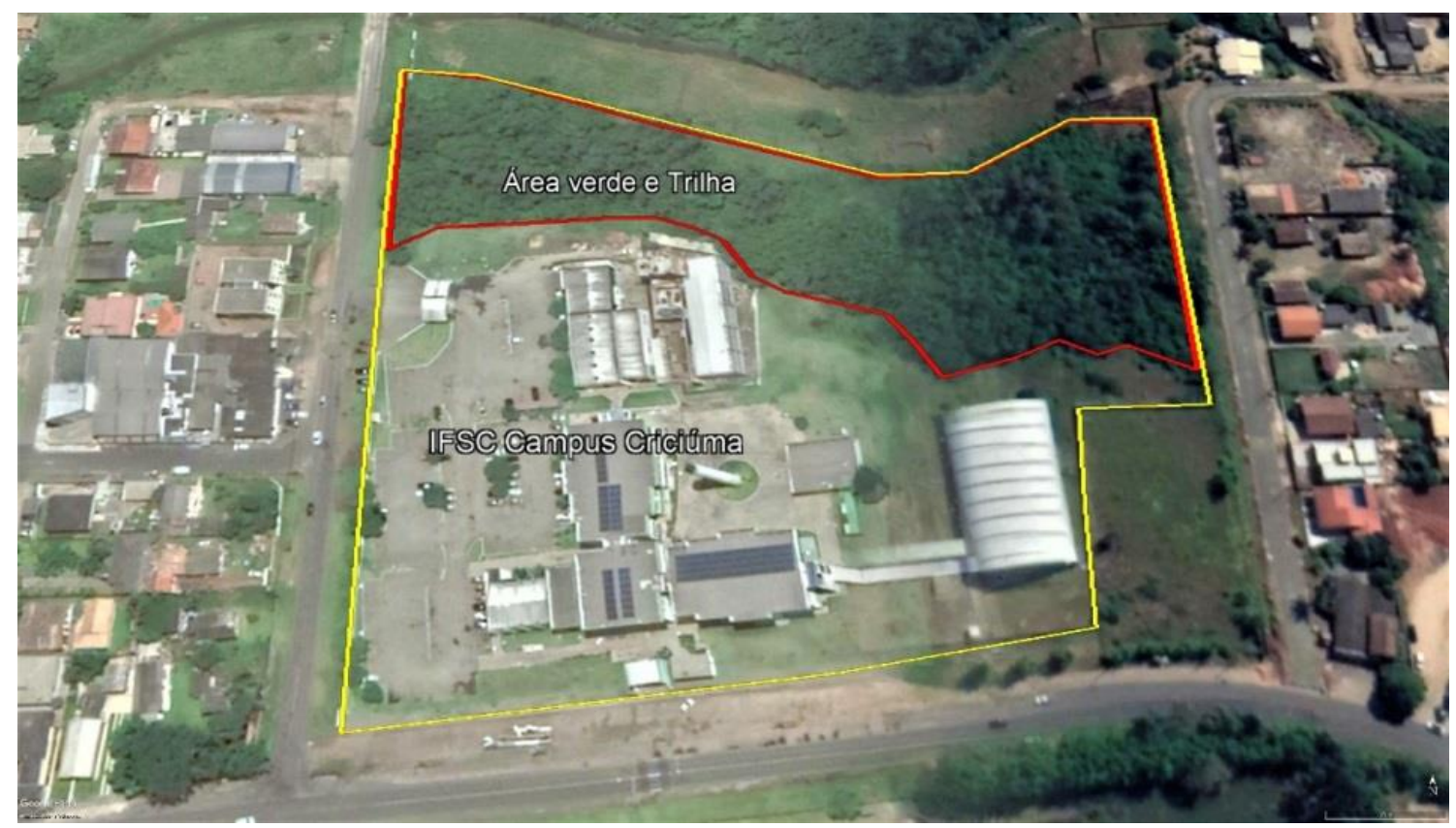

Figura 1: Vista aérea do terreno do IFSC Câmpus Criciúma, com indicação da parte da área verde onde está localizada a Trilha IFSC.

Fonte: Google Earth Pro, Versão 7.3.3.7699, 2020. 
A área sofreu intensa interferência antrópica nas décadas passadas e, atualmente, encontra-se em processo de regeneração, com a presença de espécies nativas, como canelas, figueiras e palmiteiros, além de um rico banco de mudas e algumas espécies exóticas (Figura 2). Na área também já se pode observar a presença de fauna residente, especialmente de aves.

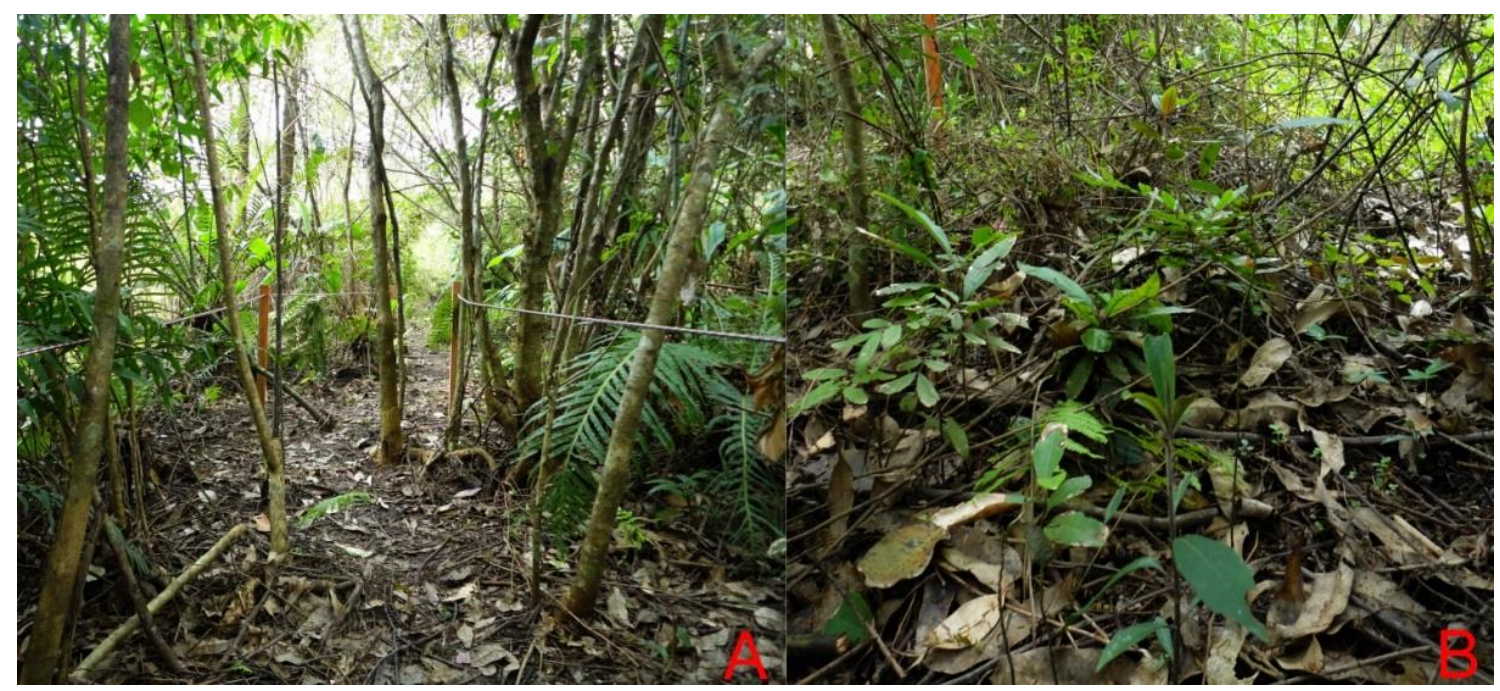

Figura 2: Vista geral do interior da trilha, com destaque para espécies nativas pioneiras e perenes $(A)$ e o banco de mudas em meio à serapilheira $(B)$.

Fonte: Arquivo do projeto "Na trilha do desenvolvimento sustentável", 2019.

Em 2014, reconhecendo a importância das áreas verdes para a qualidade da vida urbana e para a Educação Ambiental, foi realizado o projeto de extensão "Áreas verdes urbanas: espaços de Educação Ambiental e científica" com o objetivo de valorizar e utilizar a área verde do IFSC Câmpus Criciúma em atividades de extensão, ensino e pesquisa, promovendo a construção de conhecimento sobre sustentabilidade ambiental e qualidade de vida. Nessa primeira experiência, apoiada pelo Edital APROEX $n^{\circ}$ 01/2014/PROEX/IFSC, foi criada uma trilha ecológica com aproximadamente $350 \mathrm{~m}$, atualmente denominada de Trilha IFSC, e ao longo dela foram identificadas, inicialmente, 19 espécies vegetais, pertencentes a 14 famílias (ROSSO et al., 2014). Também foram preparadas exsicatas com as amostras da vegetação para serem utilizadas nas atividades de ensino e extensão, sendo que a identificação foi realizada com auxílio de literatura e de especialistas. O projeto recebeu cerca de 250 visitantes que participaram das atividades de Educação Ambiental utilizando a trilha ecológica (ROSSO et al., 2014).

Com o desenvolvimento de outros projetos e o aumento do uso da trilha por parte dos professores de biologia e geografia do Câmpus, as pesquisas foram se aprofundando. Atualmente estão identificadas 37 espécies vegetais, pertencentes a 24 famílias, sendo 31 nativas do Brasil e seis exóticas 
(Tabela 1). Também se buscou identificar a fauna, especialmente a avifauna que visita a área, da qual já se tem registro de 17 espécies nativas (Tabela 2). Informações sobre essas espécies da fauna e da flora podem ser consultadas no blog do projeto 6 nas abas "Nossa flora" e "Nossa fauna".

Tabela 1: Espécies vegetais catalogadas e identificadas com placas na Trilha IFSC.

\begin{tabular}{|c|c|c|c|}
\hline ORIGEM & FAMÍLIA & ESPÉCIE & NOME POPULAR \\
\hline \multirow{27}{*}{ 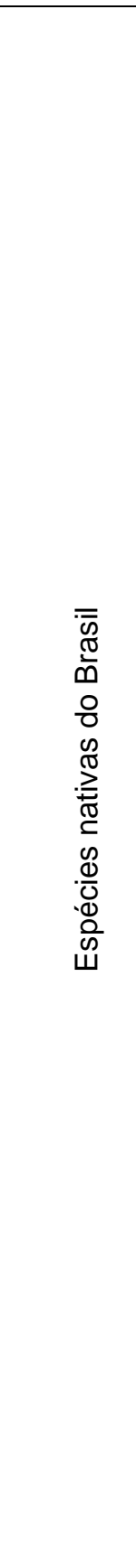 } & Acanthaceae & Justicia carnea Lindl. & \multirow{3}{*}{$\begin{array}{l}\text { Jacobina } \\
\text { Aroeira; Aroeira- } \\
\text { vermelha } \\
\text { Palmiteiro; palmito- } \\
\text { juçara }\end{array}$} \\
\hline & Anacardiaceae & Schinus terebinthifolius Raddi & \\
\hline & \multirow{2}{*}{ Arecaceae } & Euterpe edulis Mart. & \\
\hline & & $\begin{array}{l}\text { Syagrus romanzoffiana (Cham.) } \\
\text { Glassman }\end{array}$ & \multirow{6}{*}{$\begin{array}{l}\text { Caroba } \\
\text { Xaxim-miúdo } \\
\text { Grandiúva } \\
\text { Samambaiaçú } \\
\text { Leiteiro; pau- } \\
\text { leiteiro }\end{array}$} \\
\hline & Bignoniaceae & Jacaranda puberula Cham. & \\
\hline & Blechnaceae & Blechnum brasiliense Desv. & \\
\hline & Cannabaceae & Trema micrantha (L.) Blume & \\
\hline & Cyatheaceae & Alsophila setosa Kaulf. & \\
\hline & \multirow{2}{*}{ Euphorbiaceae } & Sapium glandulosum (L.) Morong & \\
\hline & & $\begin{array}{l}\text { Alchornea triplinervia (Spreng.) Müll. } \\
\text { Arg. }\end{array}$ & Tanheiro \\
\hline & \multirow{2}{*}{ Fabaceae } & $\begin{array}{l}\text { Piptadenia gonoacantha (Mart.) J.F } \\
\text { Macbr. }\end{array}$ & \multirow{2}{*}{$\begin{array}{l}\text { Jacarezeiro; pau- } \\
\text { jacaré } \\
\text { Fedegoso }\end{array}$} \\
\hline & & $\begin{array}{l}\text { Senna macranthera (DC. Ec Collad.) } \\
\text { H.S. Irwin \& Barneby }\end{array}$ & \\
\hline & Lamiaceae & Aegiphila integrifolia (Jacq.) Moldenke & $\begin{array}{l}\text { Gaioleira; pau- } \\
\text { gaiola }\end{array}$ \\
\hline & \multirow{3}{*}{ Lauraceae } & \multirow{3}{*}{$\begin{array}{l}\text { Ocotea puberula (Rich.) Ness } \\
\text { Nectranda oppositifolia Nees } \\
\text { Nectandra membranacea (SW.) } \\
\text { Griseb. }\end{array}$} & Canela guaicá \\
\hline & & & Canela amarela \\
\hline & & & Canela branca \\
\hline & Melastomataceae & $\begin{array}{l}\text { Tibouchina granulosa (Desr.) Cogn. } \\
\text { Leandra australis (Cham.) Cogn. }\end{array}$ & \multirow{5}{*}{$\begin{array}{l}\text { Quaresmeira } \\
\text { Pixirica } \\
\text { Maricá } \\
\text { Figueira branca } \\
\text { Mamica-de-cadela } \\
\text { Araçá } \\
\text { Pariparova }\end{array}$} \\
\hline & Mimosaceae & Mimosa bimucronata (DC.) Kuntze & \\
\hline & Moraceae & Ficus guaranitica Chodat & \\
\hline & Myrtaceae & $\begin{array}{l}\text { Brosimum gaudichaudil Irecul. } \\
\text { Psidium sp. }\end{array}$ & \\
\hline & Piperaceae & \multirow{2}{*}{$\begin{array}{l}\text { Piper gaudichaudianum Kunth. } \\
\text { Myrsine coriacea (Sw.) R.Br. Ex } \\
\text { Roem. \& Schult. }\end{array}$} & \\
\hline & Primulaceae & & Capororoca \\
\hline & Rutacea & Esenbeckia grandiflora Mart. & \multirow{5}{*}{$\begin{array}{l}\text { Cutia } \\
\text { Chá-de-bugre } \\
\text { Camboatá-branco } \\
\text { Camboatá } \\
\text { Jurubeba-velame } \\
\text { Quineira } \\
\text { Embaúba; pau- } \\
\text { formiga }\end{array}$} \\
\hline & Salicaceae & Casearia sylvestris Sw. & \\
\hline & Sapindaceae & $\begin{array}{l}\text { Matayba guianensis Aubl } \\
\text { Cupania vernalis Cambess. }\end{array}$ & \\
\hline & Solanaceae & $\begin{array}{l}\text { Solanum variabile Mart. } \\
\text { Solanum pseudoquina A. St.-Hil }\end{array}$ & \\
\hline & Urticaceae & Crecopia glaziovi Snethl. & \\
\hline
\end{tabular}

Continua...

${ }^{6}$ http://trilhaifsc.blogspot.com 
...continuação.

\begin{tabular}{|c|c|c|c|}
\hline ORIGEM & FAMÍLIA & ESPÉCIE & NOME POPULAR \\
\hline జ్ల & Araceae & Xanthosoma sp. & $\begin{array}{l}\text { Taioba, orelha-de- } \\
\text { elefante }\end{array}$ \\
\hline 范 & Arecaceae & $\begin{array}{l}\text { Archontophoenix cunninghamiana } \\
\text { H.Wendl. \& Drude }\end{array}$ & Palmeira real \\
\hline 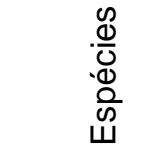 & $\begin{array}{l}\text { Euphorbiaceae } \\
\text { Musaceae } \\
\text { Myrtaceae }\end{array}$ & $\begin{array}{l}\text { Livistona chinensis (Jacq.) R. Br. } \\
\text { Ricinus communis L. } \\
\text { Musa velutina H. Wendl. \& Drude } \\
\text { Eucalyptus sp. }\end{array}$ & $\begin{array}{l}\text { Palmeira leque } \\
\text { Mamona } \\
\text { Banana-veludo } \\
\text { Eucalipto }\end{array}$ \\
\hline
\end{tabular}

Fonte: Arquivos do blog do projeto de extensão "Na trilha do desenvolvimento sustentável", disponível em <http://trilhaifsc.blogspot.com/search/label/Nossa\%20Flora>, 2020.

Tabela 2: Espécies da avifauna observadas na área verde do IFSC Câmpus Criciúma.

\begin{tabular}{lll}
\hline \multicolumn{1}{c}{ FAMíLIA } & \multicolumn{1}{c}{ ESPÉCIE } & NOME POPULAR \\
\hline Ardeidae & Egretta thula (Molina, 1782) & Garça-branca- \\
Charadriidae & Vanellus chilensis (Molina, 1782) & Quero-quero \\
Cracidae & Ortalis squamata (Lesson, 1829) & Aracuã-escamoso \\
Cuculidae & Guira guira (Gmelin, 1788) & Anu-branco \\
& Piaya cayana (Linnaeus, 1766) & Alma-de-gato \\
Furnaridae & Furnarius rufus (Gmelin, 1788) & João-de-barro \\
Picidae & Colaptes campestris (Vieillot, 1818) & Pica-pau-do-campo \\
& Melanerpes candidus (Otto, 1796) & Pica-pau-branco \\
Rallidae & Aramides saracura (Spix, 1825) & Saracura-do-mato \\
Ramphastidae & Ramphastos dicolorus Linnaeus, 1766 & Tucano-de-bico-verde \\
& Tangara sayaca (Linnaeus, 1766) & Sanhaçu-cinzento \\
Thaupidae & Coereba flaveola (Linnaeus, 1758) & Cambacica \\
& Sicalis flaveola (Linnaeus, 1766) & Canário-da-terra \\
Threskiornithidae & Phimosus infuscatus (Lichtenstein, 1823) & Maçarico-preto \\
Turdidae & Theristicus caudatus (Boddaert, 1783) & Curicaca \\
Tyrannidae & Turdus rufiventris Vieillot, 1818 & Sabiá-laranjeira \\
\hline
\end{tabular}

Fonte: Arquivos do blog do projeto de extensão "Na trilha do desenvolvimento sustentável", disponível em <http://trilhaifsc.blogspot.com/search/label/Nossa\%20Fauna>, 2020.

Em 2015 foi realizado o projeto de extensão "Na trilha da saúde", com apoio do Edital APROEX no 01/2015/PROEX/IFSC, quando foram atendidos cerca de 130 participantes com atividades de Educação Ambiental e educação para a saúde (ROSSO et al., 2015). Em 2016 e 2017 não houve execução de projeto de extensão e apenas no segundo semestre de 2017 a trilha foi utilizada em atividades de ensino em um curso de formação continuada para professores de geografia e biologia da rede estadual de ensino.

Em 2018 foi realizado o projeto de extensão "Aprender e ensinar nas

Revbea, São Paulo, V. 16, № 4: 536-553, 2021. 
águas do rio Linha Anta", apoiado pelo Edital APROEX 04/PROEX/IFSC no 01/2018, que atendeu 94 alunos e três professores, durante o qual foram utilizados nas atividades a trilha, os dados e os materiais didáticos produzidos em projetos anteriores. No mesmo ano e com continuação em 2019, foi desenvolvido o projeto de extensão "Na trilha do desenvolvimento sustentável" e "Na trilha do desenvolvimento sustentável - Ano II" (Edital PROEX/IFSC no 01/2018 e 01/2019). Em 2018 foram atendidos 215 visitantes externos, entre estudantes, professores e colaboradores de uma empresa privada, além de 150 visitantes internos entre estudantes, servidores e colaboradores terceirizados do IFSC Câmpus Criciúma, totalizando um público de aproximadamente 365 pessoas. Em 2019, foram atendidos 444 visitantes oriundos de nove escolas, sendo 344 estudantes e 29 professores do Ensino Fundamental, 66 estudantes do IFSC Câmpus Criciúma e três colaboradores de uma empresa privada. Ainda, durante a Semana Nacional de Ciência e Tecnologia (SNCT), estudantes do curso Técnico em Meio Ambiente do IFSC Câmpus Criciúma participaram do plantio de mudas de espécies arbóreas nativas da Mata Atlântica (Figura 3).



Figura 3: Plantio de mudas no IFSC Câmpus Criciúma realizada por estudantes do Curso Técnico em Meio Ambiente durante a SNCT em outubro de 2019.

Fonte: Arquivos do projeto de extensão "Na trilha do desenvolvimento sustentável", 2019.

Desde 2018, quando recebeu o título de "Na trilha do desenvolvimento sustentável", o projeto de extensão, agora em seu ano III (2020), mantém organização semelhante, que envolve atividades de manutenção da trilha e dos materiais didáticos já produzidos, criação de novos materiais didáticos, divulgação do projeto, agendamento e realização das visitas, além do registro das atividades e manutenção do blog, que já conta com mais de 5700 visitas.

As atividades de Educação Ambiental desenvolvidas com a comunidade externa começam com a recepção dos grupos no laboratório de biologia do Câmpus e uma breve apresentação do projeto, de seu objetivo e da 
equipe (Figura 4). Em seguida as turmas, geralmente em torno de 30 pessoas, são divididas em dois grupos. Um dos grupos faz atividades lúdicas no laboratório de biologia utilizando os materiais didáticos e as coleções de plantas e animais (Figura 5), enquanto o outro segue para a visita guiada na trilha, na qual são abordados temas como: a biodiversidade, sua importância e usos pelo ser humano; os ciclos ecológicos; a importância das áreas verdes urbanas e sua relação com o clima e a qualidade de vida; as bacias hidrográficas e a qualidade da água; os resíduos sólidos e sua destinação correta; entre outros (Figura 6). Em seguida as turmas são invertidas. As atividades são planejadas de acordo com a idade/série escolar e duram entre $45 \mathrm{~min}$ e $1 \mathrm{~h}$ por grupo. Em muitas visitas, quando viável, os visitantes participam do plantio de mudas como forma de exercitar o cuidado com o meio ambiente e estimular que o façam também em suas residências.

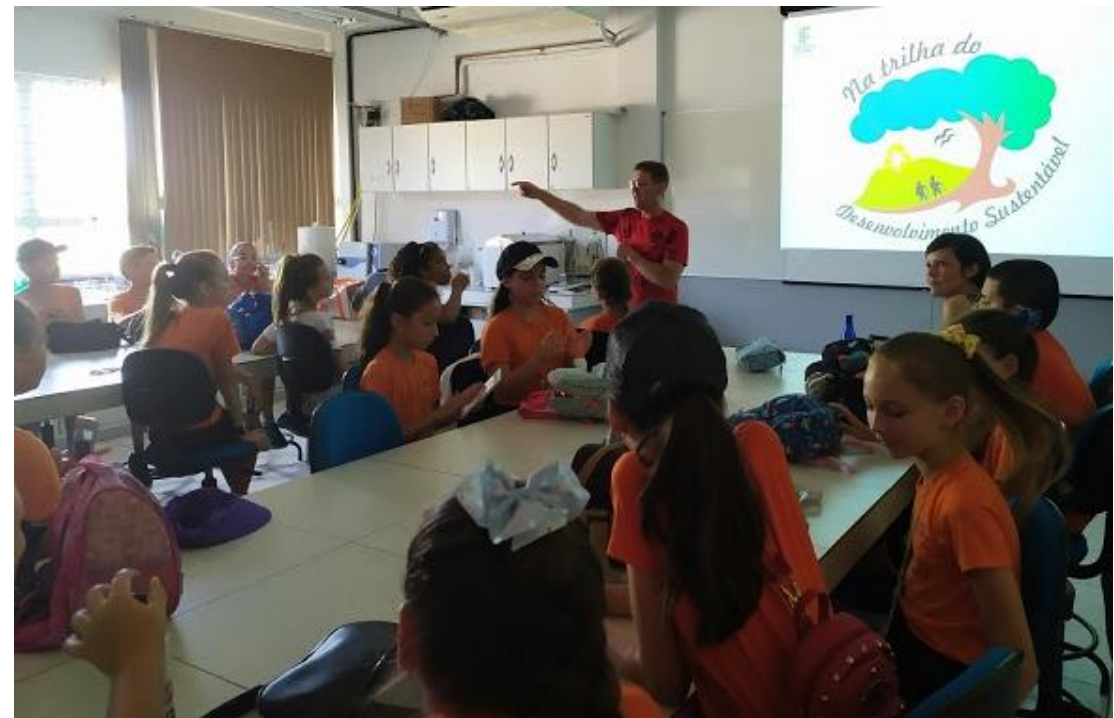

Figura 4: Atividades do projeto de extensão "Na trilha do desenvolvimento sustentável": Recepção dos visitantes no laboratório de biologia.

Fonte: Arquivos do projeto de extensão "Na trilha do desenvolvimento sustentável", 2019.

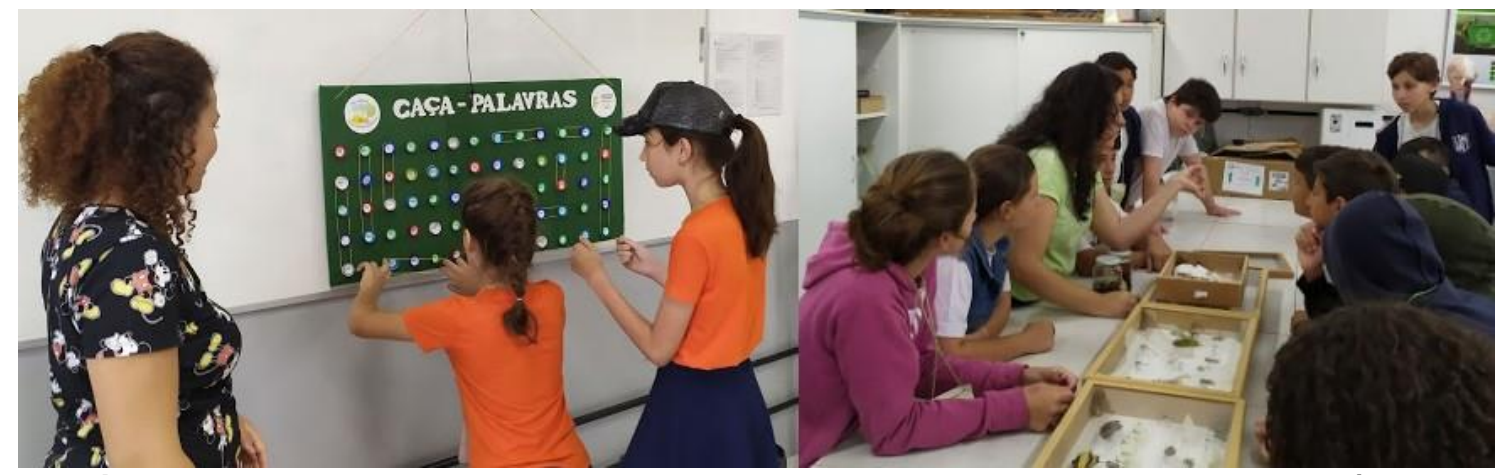

Figura 5: Atividades do projeto de extensão "Na trilha do desenvolvimento sustentável": Atividades lúdicas no laboratório de biologia.

Fonte: Arquivos do projeto de extensão "Na trilha do desenvolvimento sustentável", 2019. 


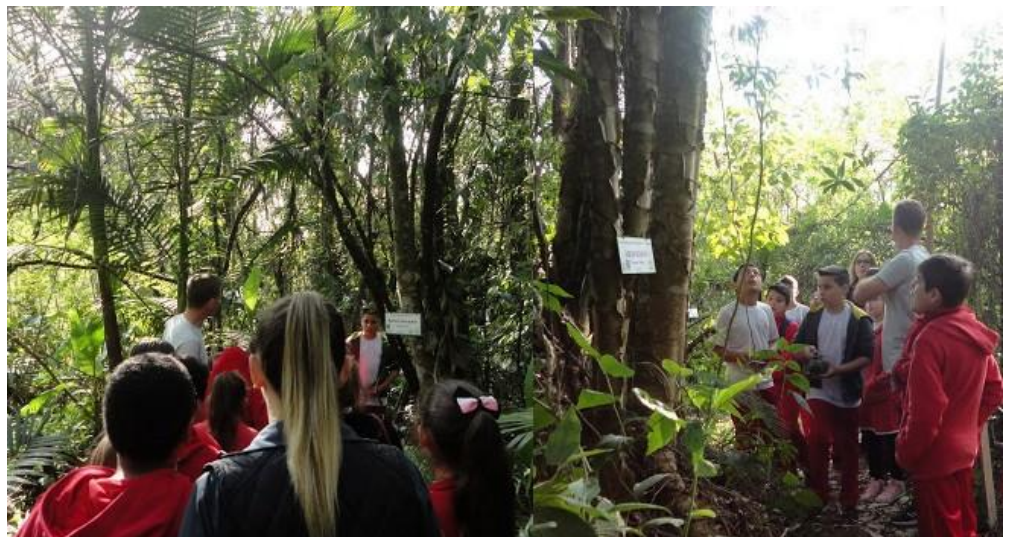

Figura 6: Atividades do projeto de extensão "Na trilha do desenvolvimento sustentável": Visita guiada na Trilha IFSC.

Fonte: Arquivos do projeto de extensão "Na trilha do desenvolvimento sustentável", 2019.

Em razão desse histórico das atividades do projeto, escolas e professores, especialmente da rede pública e vizinhas ao IFSC Câmpus Criciúma, questionam durante as visitas acerca da continuidade das atividades para o ano seguinte, pois muitos professores incluem nos seus planejamentos atividades de campo e, neste sentido, as atividades do projeto contemplam essa necessidade. Também já é prática corrente que, durante a organização das atividades agendadas, se discutam com os professores ou responsáveis pelos grupos os ajustes necessários em razão da faixa etária, do ano escolar ou do tema específico que queiram abordar.

Desde sua criação em 2014, a trilha e a área verde também têm possibilitado o uso de diferentes metodologias para o ensino e praticamente todos os cursos da instituição já tiveram a oportunidade de conhecer a trilha, seja em atividade das disciplinas de biologia ou geografia ou em atividades realizadas durante eventos promovidos no Câmpus. O mais comum e solicitado pelos alunos é percorrer a trilha com o professor, traçando um objetivo para atender o propósito de sua aula, mas também pode-se utilizar o acervo das exsicatas, o banco de dados das espécies vegetais e animais e os jogos didáticos para visualização e identificação dos conceitos vistos em sala de aula, além de outras atividades.

\section{Considerações finais}

O meio ambiente urbano proporciona uma série de facilidades para seus habitantes, como acesso à saúde, à educação e ao entretenimento. $O$ custo ambiental de tais benefícios se faz perceptível quando as pessoas dos centros urbanos procuram refúgios em áreas verdes, seja no meio rural ou na praia, com o objetivo de fugir do estresse. O contato com a natureza permite que as relações humanas com o ambiente se restabeleçam, promovendo a reflexão acerca do papel das pessoas nos ecossistemas.

Possibilitar que esse contato ocorra no próprio ambiente urbano é 
muito importante, principalmente quando acompanhado de mecanismos de Educação Ambiental. Áreas verdes, quando exploradas com a finalidade de educar a comunidade, acabam por serem preservadas e isto contribui para a regeneração da flora e da fauna, bem como de sua função ecológica. Com isso, a preservação do local é subsidiada pelo seu uso sustentável e como instrumento educativo.

O contato e a compreensão dos processos naturais na cidade são destacados por Medeiros e Alves (2019) como sendo de grande importância para o desenvolvimento e para a saúde humana desde a infância. Os autores afirmam que as pessoas devem ter o direito à natureza na cidade, para poderem usufruir e participar da construção de uma cidade como parte da natureza. Dias (2006) complementa que a observação de fenômenos naturais, como a chuva e o orvalho, estimula a sensibilidade humana e lembra que, mesmo nas cidades, a natureza está presente, basta sensibilidade para percebê-la.

Nesse contexto, o desenvolvimento deste projeto tem permitido não somente a preservação dessa área verde em meio urbano, o que por si só já é importante, mas principalmente sua utilização em atividades de Educação Ambiental que, acreditamos, têm o potencial de contribuir para que os participantes, especialmente as crianças, possam adquirir os conhecimentos e as habilidades necessárias para promover o desenvolvimento sustentável, além de estimular a mudança das atitudes e catalisar o envolvimento de todos na melhoria da qualidade de vida e na proteção do meio ambiente, conforme relatam Henrique e Rosso (2006).

Agradecimentos: Ao Instituto Federal de Santa Catarina, que por meio dos Editais APROEX no 01/2014, APROEX no 01/2015, APROEX 04 no 01/2018 e PROEX nos 01/2018, 01/2019 e 25/2019 da Pró-Reitora de Extensão e Relações Externas tem possibilitado a realização contínua das atividades.

\section{Referências}

BARGOS, D. C; MATIAS, L. F. Áreas verdes urbanas: avaliação e proposta conceitual. REVSBAU, Piracicaba (SP), v.6, n.3, p.172-188, 2011.

BARTICELLI, R.; PANDOLFO, A.; KORF, E. P. Gestão integrada de resíduos sólidos urbanos: perspectivas e desafios. Gestão \& Sustentabilidade Ambiental, Florianópolis, v. 5, n. 2, p. 711-744, out. 2016/mar. 2017.

BELOLLI, M.; QUADROS, J.; GUIDI, A. História do Carvão de Santa Catarina: 1790-1950. Criciúma: Imprensa Oficial do Estado de Santa Catarina, 2002. v. 1.

BRASIL. Lei n. 9.795, de 27 de abril de 1999. Dispõe sobre a Educação Ambiental, institui a Política Nacional de Educação Ambiental. Brasília, 1999. Disponível em: <http://www.planalto.gov.br/ccivil 03/leis/19795.htm>. Acesso em: 12 ago. 2020. 
BRASIL. Lei n. 11.428, de 22 de dezembro de 2006. Dispõe sobre a utilização e proteção da vegetação nativa do Bioma Mata Atlântica. Brasília, 2006. Disponível em: $<$ http://legislacao.presidencia.gov.br/atos/?tipo=LEl\&numero=11428\&ano=2006 \&ato $=1 \mathrm{e} 8 \mathrm{cXSq5kMRpWT08 \textrm {e }}>$. Acesso em: 18 maio 2020.

BRASIL. Lei n. 12.727, de 17 de outubro de 2012. Dispõe sobre a proteção da vegetação nativa e dá outras providências. Brasília, 2012. Disponível em: $<$ http://legislacao.presidencia.gov.br/atos/?tipo=LEl\&numero=12727\&ano=2012 \&ato=fc1ETTq1kMVpWTd43>. Acesso em: 9 jun. 2020.

BUZATTO, L.; KUHNEN, C. F. C. Trilhas interpretativas uma prática para a Educação Ambiental. Vivências, v. 16, n. 30, p. 291-231, 11 dez. 2019.

CARVALHO, J.; BÓçON, R. Planejamento do traçado de uma trilha interpretativa através da caracterização florística. Revista Floresta, v. 34, n. 1, p. 23-32, 2004.

CAVALHEIRO, F.; DEL PICCHIA, P. C. D. Áreas verdes: conceitos, objetivos e diretrizes para o planejamento. In: Congresso Brasileiro sobre Arborização Urbana, 1; Encontro Nacional sobre Arborização Urbana, 4, Vitória, ES, 1992. Anais... Vitória, SBAU, 1992. p. 29-38.

COLMAN, D. A. L.; LORENCINI JÚNIOR, Á.; VAN DAL, P. C. A Trilha Interpretativa como Atividade em Educação Ambiental: relações entre os conteúdos de ciências e o trabalho docente. In: Encontro Nacional de Pesquisa em Educação em Ciências (ENPEC), 4, 2017. Anais... Florianópolis: UFSC, 2017. Disponível em: <http://www.abrapecnet.org.br/enpec/xienpec/anais/resumos/R0962-1.pdf>. Acesso em: 20 ago. 2020.

COSTA, R. G. S.; COLESANTI, M. M. A contribuição da percepção ambiental nos estudos das áreas verdes. RA'EGA, n. 22, p. 238-251, 2011.

DIAS, G. F. Atividades interdisciplinares de Educação Ambiental: práticas inovadoras de Educação Ambiental. São Paulo: Gaia, 2006.

EISENLOHR, P. V.; MEYER, L.; MIRANDA, P. L. S.; REZENDE, V. L.; SARMENTO, C. D.; MOTA T. J. R. C.; GARCIA, L. C.; MELO, M. M. R. F. Trilhas e seu papel ecológico: o que temos aprendido e quais as perspectivas para a restauração de ecossistemas? Hoehnea, v. 40, n. 3, p. 407-418, 2013.

FIALHO, E. S. Ilha de calor: reflexões acerca de um conceito. ACTA Geográfica, Ed. Esp. Climatologia Geográfica, Boa Vista, 2012. p. 61-76.

FIGUEIREDO, R.A. A Educação para sustentabilidade: novidade ou resgate de significado? Polêmica, Questões Contemporâneas, v.12, n.4, p.830-845, 2013. GONÇALVES; T. M.; MENDONÇA, F. A. Impactos, riscos e vulnerabilidade socioambientais da produção do carvão em Criciúma/SC (Brasil). RA'EGA, n. 14, p. 55-65, 2007.

HENRIQUE, M.I.B.; ROSSO, P. Educação Ambiental e a mudança de atitudes: estudo do projeto realizado em uma escola da rede municipal de ensino de Criciúma/SC. Revista de Iniciação Científica, v. 4, n. 1, 2006. p. 171-178. 
HENRIQUES, R.; TRAJBER, R.; MELLO, S.; LIPARI, E. M.; CHAMUSCA, A. (Orgs.). Educação Ambiental: aprendizes de sustentabilidade. Brasília: Secad/MEC, 2007. 109 p. (CADERNOS SECAD 1).

INSTITUTO BRASILEIRO DE GEOGRAFIA E ESTATÍSTICA - IBGE. Sinopse do Censo Demográfico 2010: Santa Catarina, 2010. Disponível em: $<$ http://www.ibge.gov.br/censo2010/apps/sinopse/index.php?uf=42\&dados=1>. Acesso em: 25 mai. 2020.

INSTITUTO BRASILEIRO DE GEOGRAFIA E ESTATÍSTICA - IBGE. Cidades@: Criciúma. Disponível em: $<$ http://cidades.ibge.gov.br/brasil/sc/criciuma/panorama>. Acesso em: 25 mai. $2020(a)$.

INSTITUTO BRASILEIRO DE GEOGRAFIA E ESTATÍSTICA - IBGE. Cidades@: Içara. Disponível em: $<$ http://cidades.ibge.gov.br/brasil/sc/icara/panorama>. Acesso em: 25 mai. 2020(b).

JACOBI, P. Educação Ambiental, cidadania e sustentabilidade. Cadernos de pesquisa, n. 118. p. 189-205, 2003.

LEFF, E. Saber ambiental: sustentabilidade, racionalidade, complexidade, poder. Petrópolis, RJ: Vozes, 2004.

MACIEL, L. A.; SILES, M. F. R.; BITENCOURT, M. D. Alterações na vegetação herbácea de floresta ombrófila densa decorrentes do uso em uma trilha turística na Serra do Mar em São Paulo, Brasil. Acta Botânica Brasílica, n. 25, p. 628-632, 2011.

MEDEIROS, C. M. R.; ALVES, E. M. Direito à natureza na cidade: os desafios à integração com os ambientes naturais desde a infância. In: Encontro Nacional da Associação Nacional de Pós-Graduação e Pesquisa em Planejamento Urbano e Regional (ENANPUR), Anais... 38, 2019. p. 1-24. Disponível em: $<$ http://anpur.org.br/xviiienanpur/anaisadmin/capapdf.php?reqid=1399>. Acesso em: 14 out. 2020.

METTE, G.; SILVA, J. C. D.; TOMIO, D. Trilhas interpretativas na Mata Atlântica: uma proposta para Educação Ambiental na escola. Revista Eletrônica do Mestrado em Educação Ambiental, Rio Grande, RS, v. 25, p. 111-122, 2010.

MORERO, A. M.; SANTOS, R. F.; FIDALGO, E. C. C. Planejamento ambiental de áreas verdes: estudo de caso em Campinas - SP. Revista do Instituto Florestal, v. 19, n. 1, p. 19-30, 2007.

NASCIMENTO, E.P. Trajetória da sustentabilidade: do ambiental ao social, do social ao econômico. São Paulo: Estudos Avançados, v.26, n.74, p.51-64, 2012.

NUCCI, J. C. Qualidade Ambiental e Adensamento Urbano: Um estudo de Ecologia e Planejamento da Paisagem aplicado ao distrito de Santa Cecília (MSP). 2.ed. Curitiba: O Autor, 2008. 150 p. 
RAVAZZOLI, C. A problemática ambiental do carvão em Santa Catarina: sua evolução até os termos de ajustamento de conduta vigente entre os anos de 2005 e 2010. Geografia em Questão, v. 06, n. 01, p. 179-201, 2013.

ROCHA, M. F.; NUCCI, J. C. Índices de vegetação e competição entre cidades. Geousp - Espaço e Tempo. v. 22, n. 3. p. 641-655, 2018.

ROMEIRO, A. R. Desenvolvimento sustentável: uma perspectiva econômicoecológica. Estudos Avançados, São Paulo, v. 26, n. 74, p. 65-92, 2012.

ROSSO, P.; BENINCÁ, E.M.; FRAGA, F.B.F.F.; TONETTO, G.; BARBOSA, D.M. Na trilha do desenvolvimento sustentável: relato de experiência de um projeto de extensão. In: DALAZOANA, K. (Org.). Subtemas e Enfoques na Sustentabilidade. 1. ed. Ponta Grossa, PR: Atena Editora, 2020, v.2, p. 82-89. ROSSO, P.; TONETTO, G.; ZILLI, G.C.; ROSA, E.S. Educação Ambiental em espaços verdes urbanos: uma experiência no Instituto Federal de Santa Catarina, Câmpus Criciúma, SC, Brasil. In: Simpósio de Integração Científica e Tecnológica do Sul Catarinense (SICT-Sul), 3, Sombrio, SC. Anais.... v. 1. p. 402-412, 2014.

ROSSO, P.; ZILLI, G.C.; ROSA, E.S.; SILVA, G.M.; SCHUTZ, M.E.F.; TONETTO, G.; FRAGA, F.B.F.F.; MACHADO, R.; SILVA, L.A. Educação Ambiental e atividades físicas ao ar livre: trabalhando conceitos de qualidade de vida e sustentabilidade com estudantes do ensino básico. In: Simpósio de Integração Científica e Tecnológica do Sul Catarinense - (SICT-Sul), 4, 2015, Santa Rosa do Sul, SC. Anais.... v. único. p. 1588-1598, 2015.

SILVA, L.C.; LIMA, J. D. Importância das áreas verdes. In: SANTOS, M.P.; PERES, S.M.; PAULA, M.H. (Orgs.). História, cidades, redes políticas e sociais. São Paulo: Blucher, 2017. p. 91-101.

SORRENTINO, M.; TRAJBER, R.; MENDONÇA, P.; FERRARO Jr., L.A. Educação Ambiental como política pública. Educação e Pesquisa, São Paulo, v. 31, n. 2, p. 285-299, 2005.

SOS MATA ATLÂNTICA. Mata Atlântica: A casa da maioria dos brasileiros. Disponível em: <http://www.sosma.org.br/conheca/mata-atlantica>. Acesso em: 26 mai. 2020.

UNITED NATIONS DEVELOPMENT PROGRAMME - UNDP. Transformando Nosso Mundo: A Agenda 2030 para o Desenvolvimento Sustentável, 2016. Disponível $<$ http://www.undp.org/content/dam/brazil/docs/agenda2030/undp-brAgenda2030-completo-pt-br-2016.pdf>. Acesso em: 25 mai. 2020.

VELOSO, H.P.; KLEIN, R.M. As comunidades e associações vegetais da mata pluvial do sul do Brasil VI. Agrupamentos arbóreos dos contra-fortes da Serra Geral situados ao sul da costa catarinense e ao norte da costa sulriograndense. Sellowia, n. 20, p. 127-180, 1968. 